\title{
An integrated methodology for salt damage assessment and remediation: the case of San Jerónimo Monastery (Granada, Spain)
}

\author{
E. Ruiz-Agudo $\cdot$ B. Lubelli $\cdot$ A. Sawdy $\cdot$ \\ R. van Hees $\cdot$ C. Price $\cdot$ C. Rodriguez-Navarro
}

Received: 1 April 2010/Accepted: 5 July 2010/Published online: 20 July 2010

(C) Springer-Verlag 2010

\begin{abstract}
San Jerónimo Monastery (Granada, Spain) was selected as a case study for the investigation of the effect of indoor environmental conditions on salt weathering and for on-site testing of a remediation treatment using crystallization inhibitors on account of the extreme salt damage affecting both the building stone, a biomicritic limestone, calcarenite and wall paintings. A methodology combining several analysis techniques, phenomenological observations, salt and moisture analysis, environmental monitoring and thermodynamic simulations, was adopted in order to study the salt damage problems affecting this building. Within the collected samples, the majority of salts were
\end{abstract}

E. Ruiz-Agudo · C. Rodriguez-Navarro

Department of Mineralogy and Petrology, Faculty of Sciences,

University of Granada, Fuentenueva s/n, 18002 Granada, Spain

B. Lubelli $\cdot$ R. van Hees

Department of Building Systems, TNO Building and

Construction Research, Van Mourik Broekmanweg 6,

2600 AA Delft, The Netherlands

B. Lubelli · R. van Hees

Faculty of Architecture, Delft University of Technology,

Delft, The Netherlands

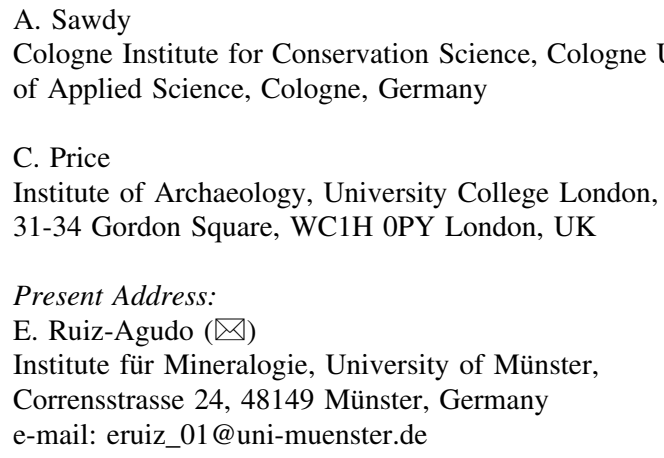

A. Sawdy of Applied Science, Cologne, Germany

C. Price

Institute of Archaeology, University College London, 31-34 Gordon Square, WC1H OPY London, UK

Present Address:

E. Ruiz-Agudo ( $\square)$

Institute für Mineralogie, University of Münster,

Corrensstrasse 24, 48149 Münster, Germany

e-mail: eruiz_01@uni-muenster.de

Cologne Institute for Conservation Science, Cologne University found to be magnesium sulphate in the form of either hexahydrite or epsomite, depending on the climate conditions, together with minor amounts of gypsum, nitrates and chlorides. Comparison of empirical observations with thermodynamic simulations of the salt mixture behaviour clearly showed that salt-induced damage events take place during the seasonal changes from spring to summer and winter to spring. An aqueous solution of an organic phosphonate, which in laboratory experiments was found to be an effective inhibitor of magnesium sulphate crystallization, was sprayed over a selected test area of unpainted stonework at the site. Preliminary results seem to indicate that after the application of the treatment both the amount of efflorescence and ongoing damage to the stone support is reduced. However, long-term monitoring of the future condition of the test area is needed to confirm whether indeed this treatment is appropriate and effective in reducing salt damage at this case study site. The outcome of this study extends beyond the particular problems at San Jerónimo Monastery, as it demonstrates a methodological approach for the study and evaluation of salt weathering problems affecting cultural heritage.

Keywords Salt damage - Crystallization inhibitors · Environmental monitoring - Thermodynamic simulations

\section{Introduction}

Salt weathering is a major decay mechanism affecting historic architecture and statuary, as well as modern buildings, roads, dams and other structures (Winkler 1994; Goudie and Viles 1997; Rodriguez-Navarro and Doehne 1999). The most damaging salts are often highly soluble in water and are transported within the porous material by 
Fig. 1 a Exterior and $\mathbf{b}$ interior views of S. Jerónimo Monastery (Granada, Spain). c Selected study area, located on the righthand side of the main altar, church of San Jerónimo Monastery. Efflorescence sampling as well as drilling was performed at points (black dots) indicated in the figure

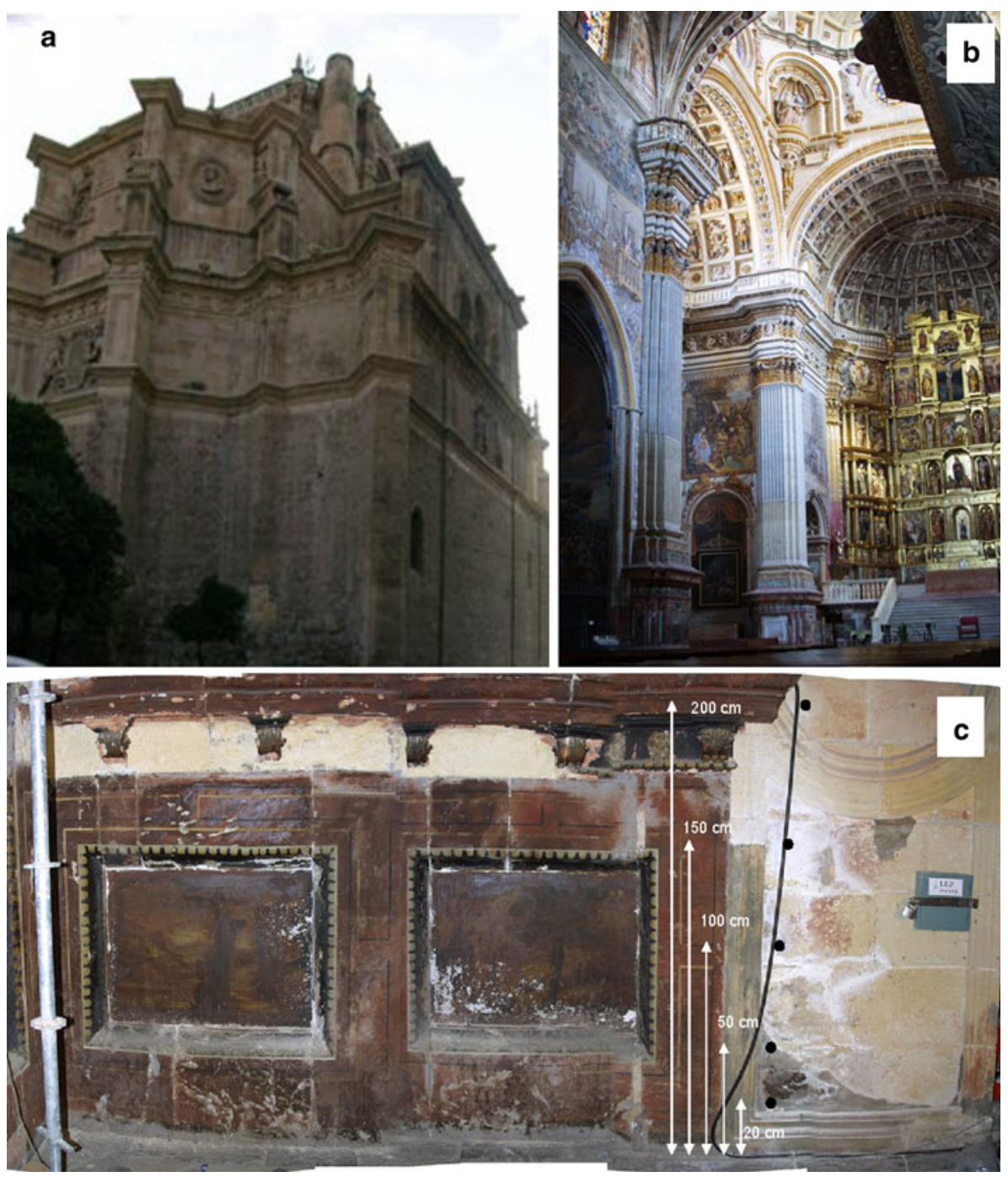

water. The physical processes (i.e. crystallization pressure) resulting in salt damage to porous building stone are normally associated with the drying of the porous material as well as fluctuations in relative humidity, both of which result in salt phase transitions and crystallization. Many conservation treatments have been developed in the past for the consolidation and protection of porous stones affected by salt weathering. However, the majority have turned out to be only partially successful; they did not fully stop the development of salt damage (Price 1996) but sometimes even enhanced salt weathering. This is mainly due to the lack of a fundamental knowledge of the underlying mechanisms of salt weathering. In this sense, significant progress has been achieved in the past decades (see for example the works by Steiger $(2005 a, b)$ and references therein). However, despite our improved theoretical understanding of salt damage processes, this is rarely applied to real case studies of salt deterioration in cultural heritage. In this paper, a series of site investigations were undertaken to assess the dynamic behaviour of the salts within the surface of the stone in combination with recording of environmental conditions and deterioration phenomena. This gives useful indications for conservation purposes (Arnold and Zehnder 1991; Laue 2005). By adopting such an approach, it is possible to correlate qualitative empirical observations with scientific measurements, to identify not only the type and amount of salts present, but also the environmental conditions under which the salt damage is activated (Sawdy and Price 2005a, b).

S. Jerónimo Monastery (Granada, Spain) (Fig. 1) was selected for investigations of interior salt weathering phenomena due to the extreme salt damage that currently affects the stone, the plaster layers and the wall paintings in the main chapel interior, near the altarpiece (Cardell-Fernández 1998). The salt damage at S. Jerónimo appears in the form of severe disaggregation and delamination of the surface plaster layers, stonework and mortar joints. In addition, abundant salt efflorescences are visible on the interior walls of the main 
chapel, on both sides of the altarpiece and also in the upper areas of the building at clerestory level. The lithotype most frequently found in the monument and also the most affected by salt problems is a biomicritic limestone (calcarenite). The calcarenite was quarried in the Santa Pudia area $(15 \mathrm{~km} \mathrm{SW}$ from Granada), and at $\mathrm{S}$. Jerónimo has been widely used throughout the building, in walls, windowsills, vaults and carved figures. The calcarenite is buff coloured, quite porous and easy to quarry and carve. These characteristics have given this stone a prominent status as a building material in Granada city (Rodriguez-Navarro 1994). It includes abundant red algae, shells of benthic foraminifera, mollusk, seeurchin spicules, serpullids and briozoans. The bioclasts are cemented by micritic calcium carbonate. Mercury intrusion porosimetry analysis of pore size distribution of the calcarenite showed that macropores are very abundant in this stone, with a mean pore radius of ca. $10 \mu \mathrm{m}$; however, smaller pores with secondary maxima at ca. 1 and $0.04 \mu \mathrm{m}$ were also detected (Ruiz-Agudo et al. 2007). The presence of both types of pores makes this stone relatively susceptible to salt weathering (Rossi Menaresi and Tucci 1991). Hydric tests have shown that while the calcarenite rapidly absorbs water, it does not dry that fast (Rodriguez-Navarro 1994). As a result, salt solutions are rapidly taken up, but remain within the stone pore system for enough time to precipitate as harmful subflorescences. This behaviour contributes to the overall susceptibility of this limestone towards salt weathering (Cardell et al. 2008).

Recently, it has been proposed that additives which modify the crystallization process could be used to reduce salt weathering (Rodriguez-Navarro et al. 2000; Selwitz and Doehne 2002; Rodriguez-Navarro et al. 2002). These additives can inhibit or promote salt crystallization within porous materials. In the first case, an increase is observed in the period between the establishment of supersaturation and the formation of a new phase at a higher critical supersaturation. Such increased induction times make it possible for the saline solution to reach the surface of the porous stone prior to the onset of crystallization. Once the solution reaches the surface, crystallization of less harmful efflorescence takes place. In contrast, when additives promote crystallization, salt precipitation occurs within the pores at low supersaturation, and thus the crystallization pressure is reduced. As a consequence, damage to the substrate is also potentially reduced. The research presented in this paper was carried out within the SALTCONTROL project (EU Project no. 501517, Contract SSP1-CT-2003-501571), which focused on the study of the behaviour of crystallization inhibitors when applied to salt laden porous building materials. In the framework of this project, a multi-disciplinary approach was adopted to study the amount, composition and mobility of salts present within the building stone as a function of location, depth and time, with the purpose of obtaining a clear picture of the current salt behaviour, its seasonal variability within the study areas in relation to the environmental conditions recorded and also the possible sources of salts. The final aims of this work were to establish a methodology for the assessment of salt decay and to evaluate of the possibility of slowing the development of salt damage through the use of crystallization inhibitors.

\section{Methodology}

Sampling campaigns and damage assessment

The pillar on the south side of the altar, facing the nave was chosen as pilot area for monitoring moisture and salt distribution as well as for treatment with the selected inhibitor (Fig. 1c). The calcarenite stone of the pillar and the painted plaster showed severe salt damage, which has rapidly increased in recent years (see the study performed in the building by Cardell-Fernández (1998)). A telemetric environmental monitoring system was installed in the chapel to record relative humidity, ambient and surface temperature at the ground level (pilot area), the clerestory level and outside of the building (roof). A total of eight site visits were undertaken at approximately three monthly intervals between September 2004 and October 2006. During each site visit, a damage survey of the test area was performed, by means of graphic documentation of the deterioration phenomena, salt sampling and collection of environmental monitoring data. Aspects related to the evolution of salt damage, in particular the distribution and morphology of salt efflorescences, were recorded onto a photographic base map, and then digitally transferred using vector graphics software (Adobe Illustrator). Image analysis of the digitised graphic documentation was undertaken (using ImageJ $1.37 \mathrm{v}$ available from the National Institute of Health, USA, http://rsb.info.nih.gov/ij/) to estimate the abundance of salt efflorescences at each site visit in terms of the surface area of the object covered by efflorescences.

\section{Moisture and salt distribution}

The moisture distribution was investigated by taking drilling powder samples at different heights (from 0 up to $200 \mathrm{~cm}$ above the floor level) and depths (from the surface to $20 \mathrm{~cm}$ in depth) in the wall. This was done twice over the studied period: a first campaign was performed in September 2004 and a second one in June 2006. Sampling was restricted to the same substrate material (the calcarenite stone) to ensure that a reliable profile of the moisture distribution was obtained. Additional samples were taken from a mortar joint, at a height of $125 \mathrm{~cm}$. The powder 
samples were dried in an oven at $70^{\circ} \mathrm{C}$, and their moisture content (MC) was gravimetrically determined.

A first indication of the presence and distribution of hygroscopic salts in the wall was obtained by measuring the Hygroscopic Moisture Content (HMC) of the samples at $65 \% \mathrm{RH}$, then at $80 \% \mathrm{RH}$ and finally at $96 \% \mathrm{RH}(\mathrm{Lu}-$ belli et al. 2004). Samples were moved to the next progressively higher RH regime once attainment of a constant weight. The temperature was kept constant at $20^{\circ} \mathrm{C}$. In order to obtain quantitative information regarding the amount and type of salt ions present, ion chromatography (IC) analyses for cation and anion determination were performed using a Dionex ICS 90 chromatographer at the University of Eindhoven on a selection of 19 of the powder samples collected during the first sampling campaign.

To assess the distribution and evolution of efflorescences and salts in the surface region (i.e. up to $1 \mathrm{~cm}$ depth), samples were taken by dry brushing (for efflorescences) and micro-drilling the stone at different heights (20, 50, 100, 150 and $200 \mathrm{~cm}$ above floor level). A hand drill with a $0.65 \mathrm{~mm}$ diameter drill bit was used to obtain samples at the following depth intervals: $0-2,2-4$, and 4-10 $\mathrm{mm}$. The aqueous ion content of the samples was then determined using IC (Dionex ICS 90, University of Eindhoven) and inductively coupled plasma atomic emission spectroscopy (ICP-AES) (Institut für Mineralogie, University of Münster). Aqueous ion analytical data was statistically analysed to investigate the salt content distribution and its variability over time within the surface layers. Analysis of variance (ANOVA) techniques using a general linear model (GLM) were used to assess the degree to which the salt content of the stone varied over time, and also with respect to sampling height and depth. This technique provides a means of verifying that reported data trends are in fact real and not due to experimental error, and also of assessing the effect of multi-factor interactions. Efflorescence samples were collected and stored in airtight plastic bags and bottles, and analysed by means of XRD
(Philips PW 1547 diffractometer, Dept. Mineralogy and Petrology, University of Granada) and ESEM-EDX (Philips Quanta 400, CEAMA, University of Granada and Junta de Andalucía).

Treatment with crystallization inhibitor and assessment of its effectiveness

Two areas, located between 100 and $150 \mathrm{~cm}$ height (Fig. 2a), showing similar amount and distribution of efflorescences were selected within the pilot area for testing the proposed inhibitor treatment. The selected area for treatment application was first visually inspected and the presence of efflorescences recorded photographically prior to the application of the inhibitor. Efflorescences were mechanically removed with a soft brush, and the amount of salts and material loss (insoluble material) in each area collected and quantified. Both areas had similar amount of efflorescences (Table 1). The selected areas were then sprayed with deionised water (control area) and DTPMP (diethylenetriaminepentakismethylphosphonic acid) $0.01 \mathrm{M} \mathrm{pH} 8$ aqueous solution (treatment area), until no further absorption of the solution was observed $(0.13$ and $0.21 \mathrm{~mL} \mathrm{~cm}^{-2}$ for control and treatment area, respectively). The selection of the inhibitor as well as the application conditions ( $\mathrm{pH}$ and concentration) was based on the result of preliminary laboratory tests (Ruiz-Agudo et al. 2008). The program for treatment application was as follows: (1) June 2006-first application; (2) October 2006-second application; and (3) January 2007-third application.

\section{Results and discussion}

\section{Moisture distribution}

Moisture (MC) and hygroscopic moisture (HMC) distribution during the first sampling campaign are shown in
Fig. 2 Evolution of efflorescences in the selected area for treatment application: a before application (June 2006); b after first application in October 2006 and $\mathbf{c}$ after second application in January 2007. The upper box delimits the area in which the inhibitor was applied, while the lower one shows the control area sprayed with water
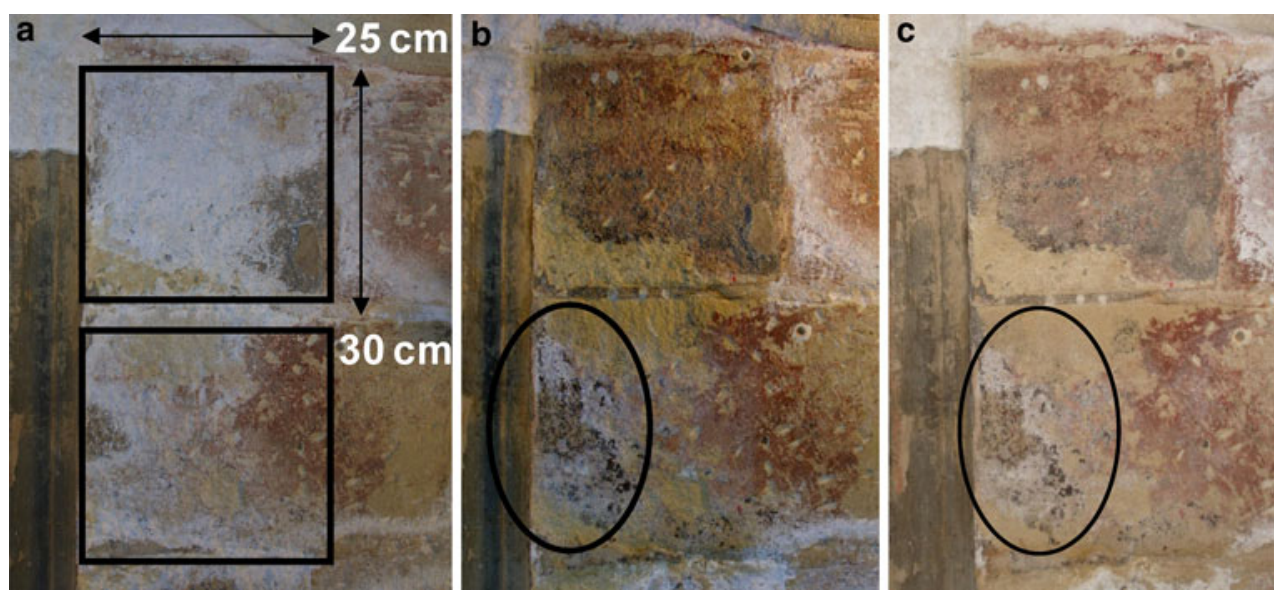
Table 1 Quantification of efflorescences and material loss in areas selected for in situ inhibitor treatment applications

\begin{tabular}{lllll}
\hline & $\begin{array}{l}\text { Wet efflorescences } \\
\left(\mathrm{mg} / \mathrm{cm}^{2}\right)\end{array}$ & $\begin{array}{l}\text { Dried efflorescences } \\
\left(\mathrm{mg} / \mathrm{cm}^{2}\right)\end{array}$ & $\begin{array}{l}\text { Insoluble material } \\
\left(\mathrm{mg} / \mathrm{cm}^{2}\right)\end{array}$ & $\begin{array}{l}\text { Salts } \\
\left(\mathrm{mg} / \mathrm{cm}^{2}\right)\end{array}$ \\
\hline Control area & & & & \\
June 2006 (before treatment) & 19.20 & 13.45 & 3.20 & 10.21 \\
October 2006 & 0.81 & 0.65 & 0.13 & 0.57 \\
January 2007 & 0.73 & 0.59 & 0.40 & 0.19 \\
Treated area & & & 1.77 & 11.69 \\
June 2006 (before treatment) & 20.40 & 13.67 & 0.45 & 0.59 \\
October 2006 & 1.31 & 1.15 & 0.24 & 0.15 \\
January 2007 & 0.43 & 0.39 & & \\
\hline
\end{tabular}

Fig. 3 Moisture content (MC) and hygroscopic moisture content at $96 \% \mathrm{RH}$, as measured on samples taken at different heights and depths during the first (a) and second (b) sampling campaign at the test site

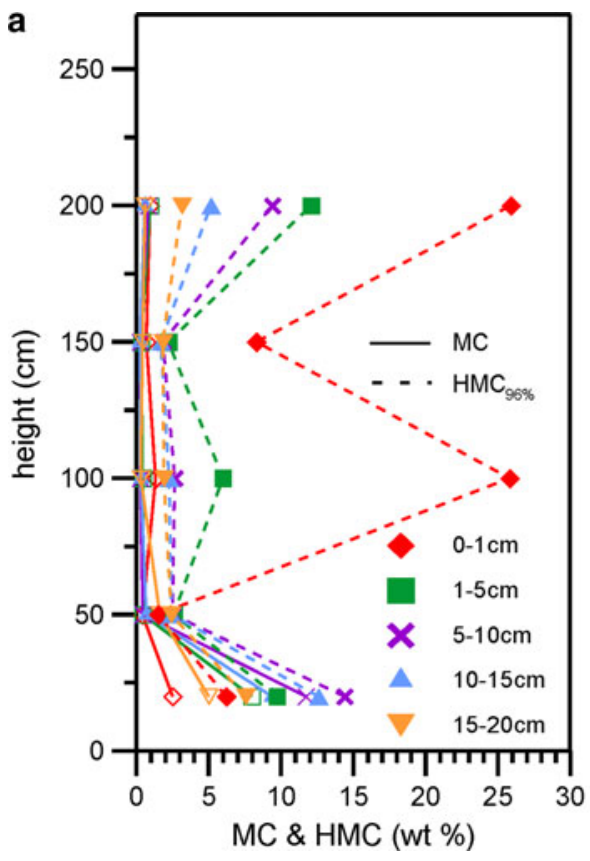

Fig. 3a. There is a high MC (up to $12 \mathrm{wt} \%$ ) in depth in the wall at $20 \mathrm{~cm}$ above the floor level. When comparing the MC distribution with the HMC distribution, it is possible to conclude that, as the MC is always lower than the HMC, the moisture content in the wall is mainly due to the presence of hygroscopic salts. Rising damp, if present, does not reach a level higher than $20 \mathrm{~cm}$. An additional moisture source is present at the surface, which might be associated with the cleaning regime within the church (i.e. washing the floor). No relevant differences between the moisture content in the stone and in the bedding mortar have been found.

It should be mentioned that the floor in the church lies about $150 \mathrm{~cm}$ lower than the ground level outside the church. Next to the church there is a garden with orange trees which is regularly irrigated. Nevertheless, the moisture distribution measured in the wall does not show any peak at $150 \mathrm{~cm}$ which could have suggested water penetration from the garden into the church wall. In order to check whether the height reached by the moisture in the wall was subjected to seasonal variations, a second sampling campaign was performed after a rainy period. Similar results were obtained (Fig. 3b), confirming the overall low $\mathrm{MC}$ in depth in the wall and therefore the absence of rising damp as major moisture source.

\section{Salt distribution}

\section{Salt distribution in depth}

The hygroscopic moisture distribution (Fig. 3) shows that salts are mainly located in the outer layer of the wall, where they accumulate due to evaporation. The distribution of salts through the height of the wall is less clear. Salts accumulate not only in the lower part of the masonry, but also at a higher level in the wall. The salt accumulation at $200 \mathrm{~cm}$ is difficult to explain, since the MC of samples taken even after a rainy period showed that rising damp 
never reaches such a height in the wall. Besides, the HMC distribution does not show a gradual increase, as expected in the case of salt transported by rising damp, but two clearly distinct high salt content zones interrupted by a zone without salts: this suggests the presence of an additional moisture source at a higher level in the wall transporting the salt from the inner part of the wall to the surface. Nevertheless, the MC distribution cannot confirm this hypothesis. We can suppose either that in the past water penetration occurred (e.g. from the adjacent ground), dissolving and transporting the salt to the surface, but at the time of the present study this moisture source was no longer extant (although it is complicate that moisture from the irrigation has transported salts to the surface through a 2-m-thick wall without leaving any trace behind) or that salts, originating for example from repair materials, have penetrated from the surface towards the inner part of the wall. However, this last hypothesis is also unlikely, as no recorded conservation treatments have been applied in the selected area. Therefore, the source of these salts remains unclear.

The IC analyses performed on a selection of samples (Fig. 4) show the presence of large quantities of $\mathrm{Ca}$ and $\mathrm{SO}_{4}$, which are due to the presence of a gypsum $\left(\mathrm{CaSO}_{4} \cdot 2 \mathrm{H}_{2} \mathrm{O}\right)$ plaster in the area, mainly in the lower part of the wall. Chlorides were also found. At a height of 100 and $150 \mathrm{~cm}$ from the floor, $\mathrm{Mg}$ ions were found in combination with $\mathrm{SO}_{4}$ ions, which suggests the presence of magnesium sulphate. This hypothesis was confirmed by the XRD analysis of efflorescences (see below). At $250 \mathrm{~cm}$ the salt ions present form a very hygroscopic salt mix, since in

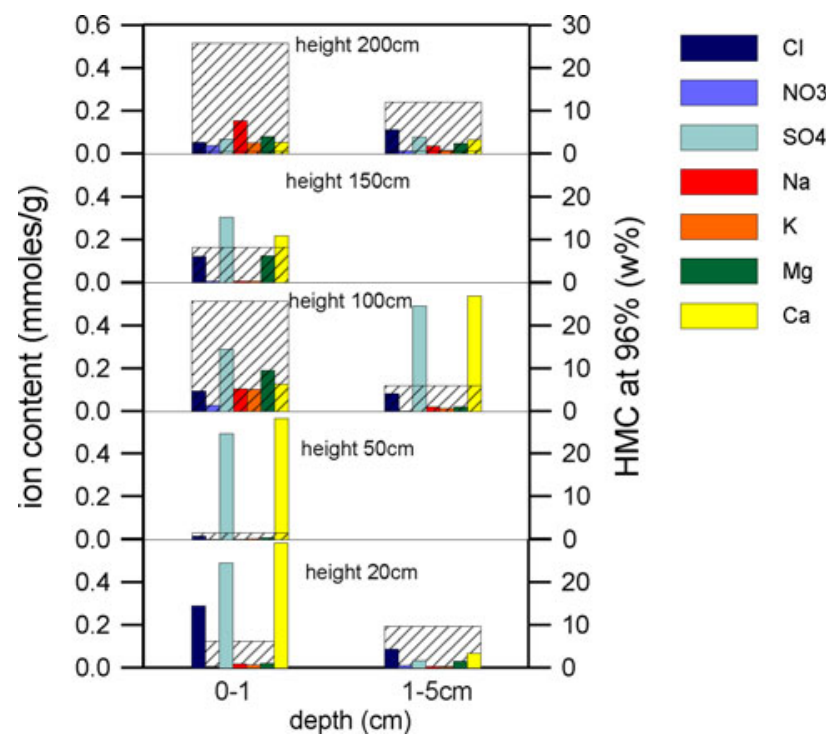

Fig. 4 Ion content determined by ionic chromatography at different depths and heights in the wall at the test site spite of the relatively low ion content a high HMC has been measured.

The temporal evolution of the salt distribution in depth has been investigated by comparing the HMC measured in the samples collected in September 2004 (after a dry season) and in June 2006 (after a rainy season). The results are reported in Fig. 5. From the graph it is possible to conclude that the HMC distribution changes significantly only at the height of $20 \mathrm{~cm}$. Most probably the rain has provided additional water which penetrated the wall by capillary rise, and has dissolved the salts and transported them to the surface. At a higher level the new HMC values are different from the old ones (particularly in the outer layers of the wall), but the trends of the HMC distribution with depth do not change significantly.

\section{Salt distribution near the surface}

Line graphs of the mean values for sulphate, chloride and nitrate are shown in Fig. 6 to illustrate the distribution of salts with respect to sampling height, depth and time. The vertical distribution of salts within the stone to some degree approximates to Arnold and Zehnder's model of fractionation according to salt solubility (Arnold and Zehnder

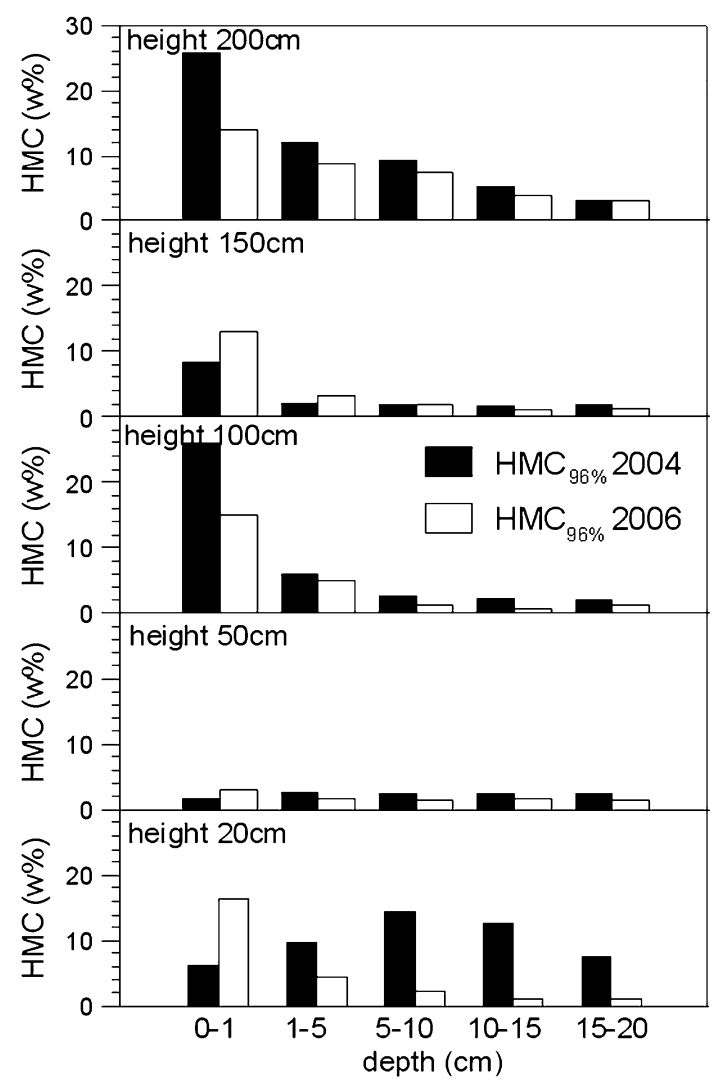

Fig. 5 HMC distribution at the test site after a dry (2004) and a rainy (2006) season 
Fig. 6 IC analysis of surface salts. Salt distribution as a function of a height and b sampling depth. Sulphate c including and $\mathbf{d}$ excluding gypsum, e chloride and $\mathbf{f}$ nitrate distribution as a function height a St. Jeronimo, Granada: Salt distribution Area 2, sampling height $50-200 \mathrm{~cm}$

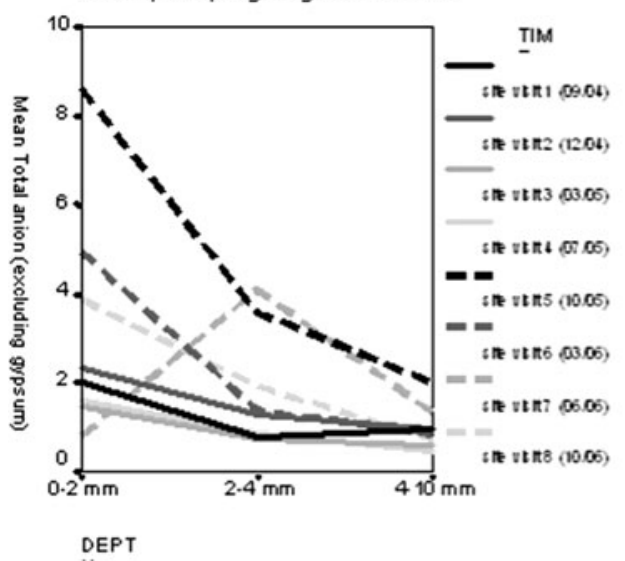

St Jeronimo, Granada: sulphate (induding gypsum

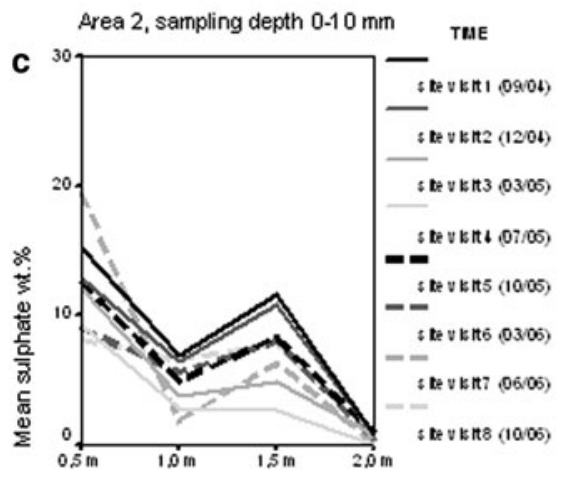

SAMPLING HEIGHT

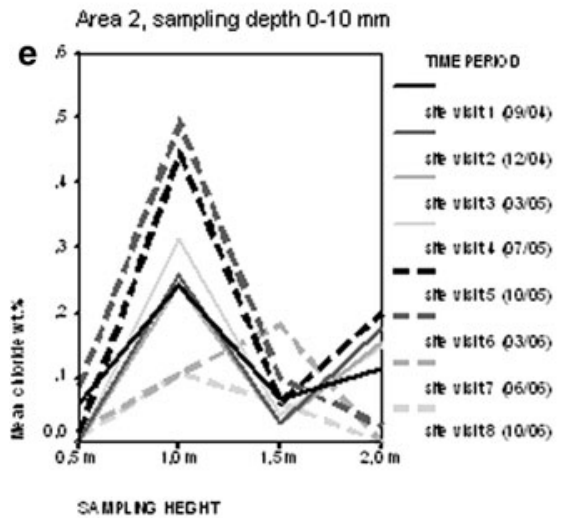

b St. Jer onimo: salt distribution

Area 2, sampling depth $0-10 \mathrm{~mm}$

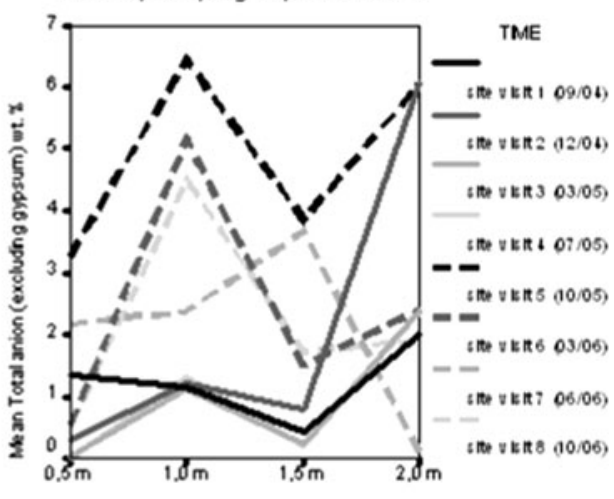

HEGHT

St Jeronimo, Granada: sulphate (exduding gypsum) Area 2, sampling depth $0-10 \mathrm{~mm}$

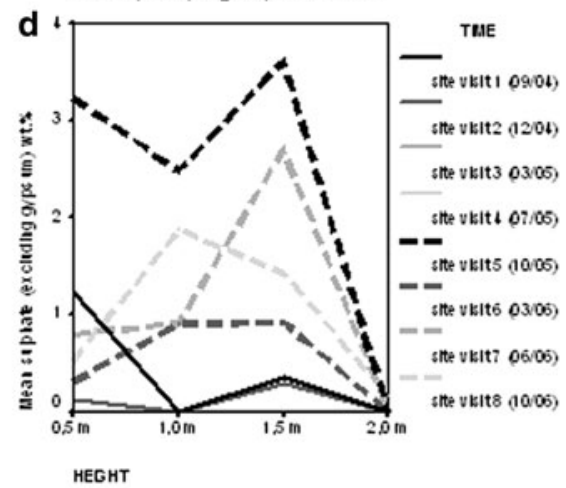

St Jeronimo, Granada: nitrate distribution Area 2, sampling depth $0-10 \mathrm{~mm}$

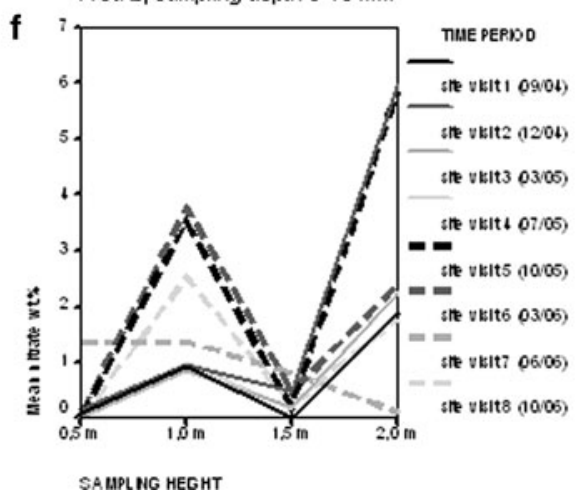

1991) in that less soluble sulphates (i.e. gypsum, as shown in Fig. 6a) are accumulated at the base of the wall, while chlorides are located predominantly in the middle region of the wall, and nitrates at the top. However, there are also noticeable anomalies in the distribution that do not fit with Arnold and Zehnder's model, most particularly associated with the distribution of sulphates other than gypsum (see Fig. 6b): while there is some accumulation of sulphates at the base of the wall, in general the sulphate levels are at their highest at around $150 \mathrm{~cm}$. Moreover, there is a double peak in the nitrate distribution, showing an accumulation of nitrates at $100 \mathrm{~cm}$. This is in agreement with the analysis of samples taken deeper within the wall (above), and confirms that in addition to capillary rise from the base of the wall, there has been an additional supply of salts to the middle zone of the wall.

The results of the ANOVA statistical analysis given in Table 2 conclusively show that during the study period 
Table 2 Univariate analysis of variance (ANOVA) of the total anion content $(\mathrm{wt} \%)$ in micro-drilling samples (excluding gypsum) to determine significance of time (TIME), sampling depth (DEPTH) and sampling height (HEIGHT)

\begin{tabular}{ll}
\hline Factor/multi-factor interaction & Significance $^{\mathrm{a}}$ \\
\hline TIME & 0.000 \\
DEPTH & 0.000 \\
HEIGHT & 0.000 \\
TIME $\times$ DEPTH & 0.001 \\
TIME $\times$ HEIGHT & 0.016 \\
DEPTH $\times$ HEIGHT & 0.393 \\
TIME $\times$ DEPTH $\times$ HEIGHT & 0.324 \\
\hline
\end{tabular}

Sampling heights 50-200 cm; sampling depths 0-10 mm

${ }^{\text {a }}$ Significance values can be read as the probability (out of 1) that the result could have been produced randomly, e.g. if a factor has a significance of 0.05 , this means that there is only a $5 \%$ chance that the result could have been due to random error-i.e. there is a $95 \%$ probability that the factor in question had a genuine influence on the results. Thus, the lower the significance value, the more significant the factor is

Table 3 Univariate Analysis of Variance (ANOVA) of the total anion content (wt\%) in micro-drilling samples (excluding gypsum) to determine significance of time (TIME), sampling depth (DEPTH) and sampling height (HEIGHT)

\begin{tabular}{ll}
\hline Factor/multi-factor interaction & Significance $^{\mathrm{a}}$ \\
\hline TIME & 0.026 \\
DEPTH & 0.040 \\
HEIGHT & 0.045 \\
TIME $\times$ DEPTH & 0.714 \\
TIME $\times$ HEIGHT & 0.221 \\
DEPTH $\times$ HEIGHT & 0.843 \\
TIME $\times$ DEPTH $\times$ HEIGHT & 0.794 \\
\hline
\end{tabular}

Sampling heights 50-200 cm; sampling depths 2-10 mm

${ }^{a}$ Significance values can be read as the probability (out of 1) that the result could have been produced randomly, e.g. if a factor has a significance of 0.05 , this means that there is only a $5 \%$ chance that the result could have been due to random error-i.e. there is a $95 \%$ probability that the factor in question had a genuine influence on the results. Thus, the lower the significance value, the more significant the factor is

there has been significant variation of the salt content of the stone with respect to sampling height, depth and also time (conditions of exposure). As can be seen in Fig. 6c, the outermost two millimetres of samples appear to have a much higher salt content than the rest. To determine whether this difference is indeed significant, all samples taken from the first two millimetres were excluded from the data set and another univariate ANOVA was run on remainder (Table 3). Comparing the Tables 2 and 3, it can be seen that on exclusion of the first $2 \mathrm{~mm}$, the significance of the factor 'sampling depth' is reduced (from $P=0.000$ to $P=0.040$ ). This demonstrates that the salt content of the outermost two millimetres of the stone was indeed significantly higher than the rest, after which the salt distribution becomes more uniform. A similar depth distribution pattern has also been noted elsewhere, and is typical of salt-contaminated wall paintings and stone objects (Sawdy and Price 2005b).

The ANOVA results also confirm the empirical observations made on basis of repeated graphic documentation, which indicated that the abundance and distribution of salt efflorescences varied significantly over the study period.

\section{Efflorescences}

The main salts identified by XRD in the collected efflorescences were magnesium sulphate in the form of hexahydrite or epsomite, depending on the season (i.e. rainy or drought periods), minor amounts of gypsum and nitrates and trace amounts of chlorides. These results are in agreement with those of ESEM/EDX and IC analysis (Figs. 7, 8). By combining these methods, the salts present were identified as $\mathrm{MgSO}_{4} \cdot n \mathrm{H}_{2} \mathrm{O}$ (hexahydrite and/or epsomite) and $\mathrm{CaSO}_{4} \cdot 2 \mathrm{H}_{2} \mathrm{O}$ (gypsum), $\mathrm{KNO}_{3}$ (niter), $\mathrm{NaNO}_{3}$ (nitratine), $\mathrm{Mg}\left(\mathrm{NO}_{3}\right)_{2} \cdot 6 \mathrm{H}_{2} \mathrm{O}$ (nitromagnesite) and $\mathrm{NaCl}$ (halite). The gypsum could originate from the interaction between magnesium sulphate and calcite grains of limestone (i.e. salt-related chemical weathering), although the main source of this salt seems to be the plaster that in the past covered the stone.

In the first sampling campaign (September 2004), highly soluble salts (nitrates and chlorides) were located in the wall upper area, and less soluble salts (sulphates) are found at lower levels. In particular, the amount of gypsum reaches a maximum at $50 \mathrm{~cm}$ height, while the highest amount of magnesium sulphate was found at $100-150 \mathrm{~cm}$ (Fig. 8b). The amount of total salts decreased with height in September 2004. Conversely, in October 2005, after a period of drought, the amount of salts at $2 \mathrm{~m}$ was higher than at $50 \mathrm{~cm}$ (Fig. 8a). A detailed study of the saline phase distribution revealed that, although in September 2004 the more soluble phases (i.e. nitrates) appeared at high levels and sparingly soluble salts such as gypsum appeared at the bottom of the selected area-as it is expected when capillary rise is source of humidity-this profile changed in 2005 (Fig. 8c). Sulphates were then found homogenously distributed all over the wall, and the higher concentration of nitrates appeared at a medium height. This indicates that, apart from rising damp in the lower part of the wall, there were additional sources of salts to the wall, in agreement with the results of the analysis of salts in depth and in the wall surface layer. 
Fig. 7 ESEM

microphotography and EDX microanalysis of salts: a $\mathrm{Mg}$ sulphate (possibly hexahydrite), b Mg-sulphate (possibly epsomite), c Ca-sulphate (gypsum) and $\mathbf{d} \mathrm{KNO}_{3}$ (niter)
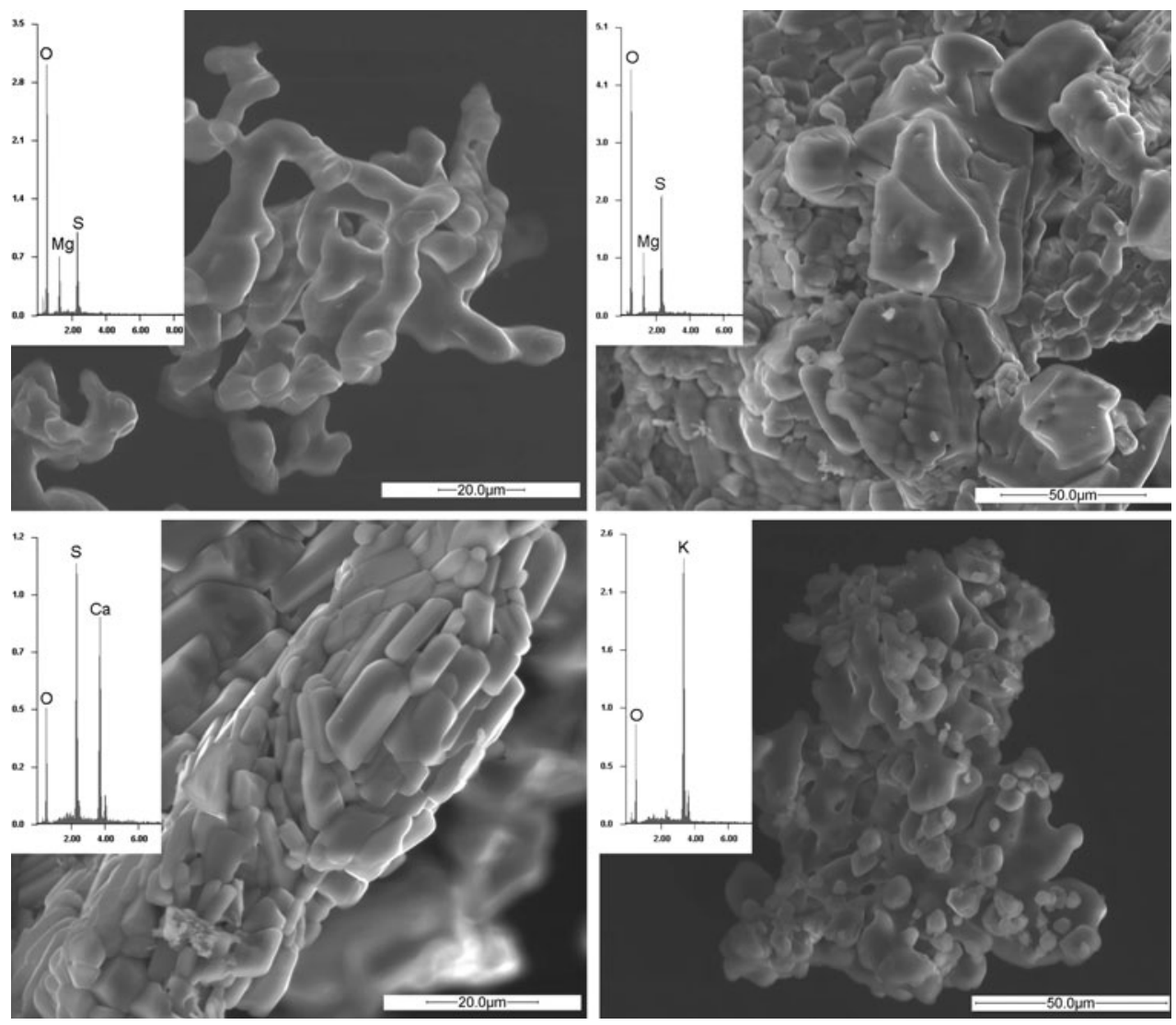

Environmental conditions and thermodynamic assessment of salt behaviour

The collected monitoring data were downloaded and imported into a spreadsheet programme for calculation of absolute humidity and dew point values and graphic presentation. From December 2004 to December 2005 the internal temperatures were between 10 and $25^{\circ} \mathrm{C}$ (the building is unheated), and the interior relative humidity sharply fluctuated around 15-65\% RH. These observations suggest that the building displays good thermal buffering, but poor hygral buffering, indicating a high degree of air exchange with exterior. The slightly higher measurements recorded at clerestory level compared with those at floor level point to a vertical stratification of ambient and surface temperature in the building during summer. Condensation events were very unlikely throughout the monitoring period. Similar observations were recorded for the second year of monitoring (2006).

The analytical data from the efflorescences (IC analysis) were subjected to thermodynamic assessment using the RUNSALT software, which is the user interface to the ECOS thermodynamic model for the prediction of the behaviour of salt mixtures under changing climate conditions (Price 2000). This was done to determine the phase transition boundaries (in terms of $\mathrm{RH}$ and temperature) for the salts present. The temperature was set to $23^{\circ} \mathrm{C}$, the average value obtained from environmental monitoring data. The relative humidity range was set from 20 to $95 \%$. RUNSALT calculates the salts which crystallise within the specified RH range. As an illustration of this calculation, phase transitions for efflorescence samples collected in September 2004 are shown in Fig. 9. Phases expected in the system according to the thermodynamic simulation are in good agreement with those identified by XRD, ESEM/ EDX and IC (see above). Considering that the system evolves from wet to dry conditions (i.e. decreasing $\mathrm{RH}$ ), in all the samples precipitation of epsomite occurs first. It is assumed that the same processes will take place in the opposite direction. It has to be mentioned here that phase transitions in the $\mathrm{MgSO}_{4}-\mathrm{H}_{2} \mathrm{O}$ system may not be accurately represented by the ECOS thermodynamic model. Moreover, the model considers just four main phases (epsomite, hexahydrite, starkeyite and kieserite), under typical ambient conditions, but it is likely that several other metastable hydrates occur in magnesium sulphateladen materials (Steiger et al. 2008). The deliquescence humidities of these phases are not accurately known to unambiguously predict the behaviour of a mixture of magnesium sulphates. Furthermore, there is significant hysteresis in $\mathrm{MgSO}_{4} \cdot n \mathrm{H}_{2} \mathrm{O}$ transitions, and it has been reported that although according to the phase diagram of 

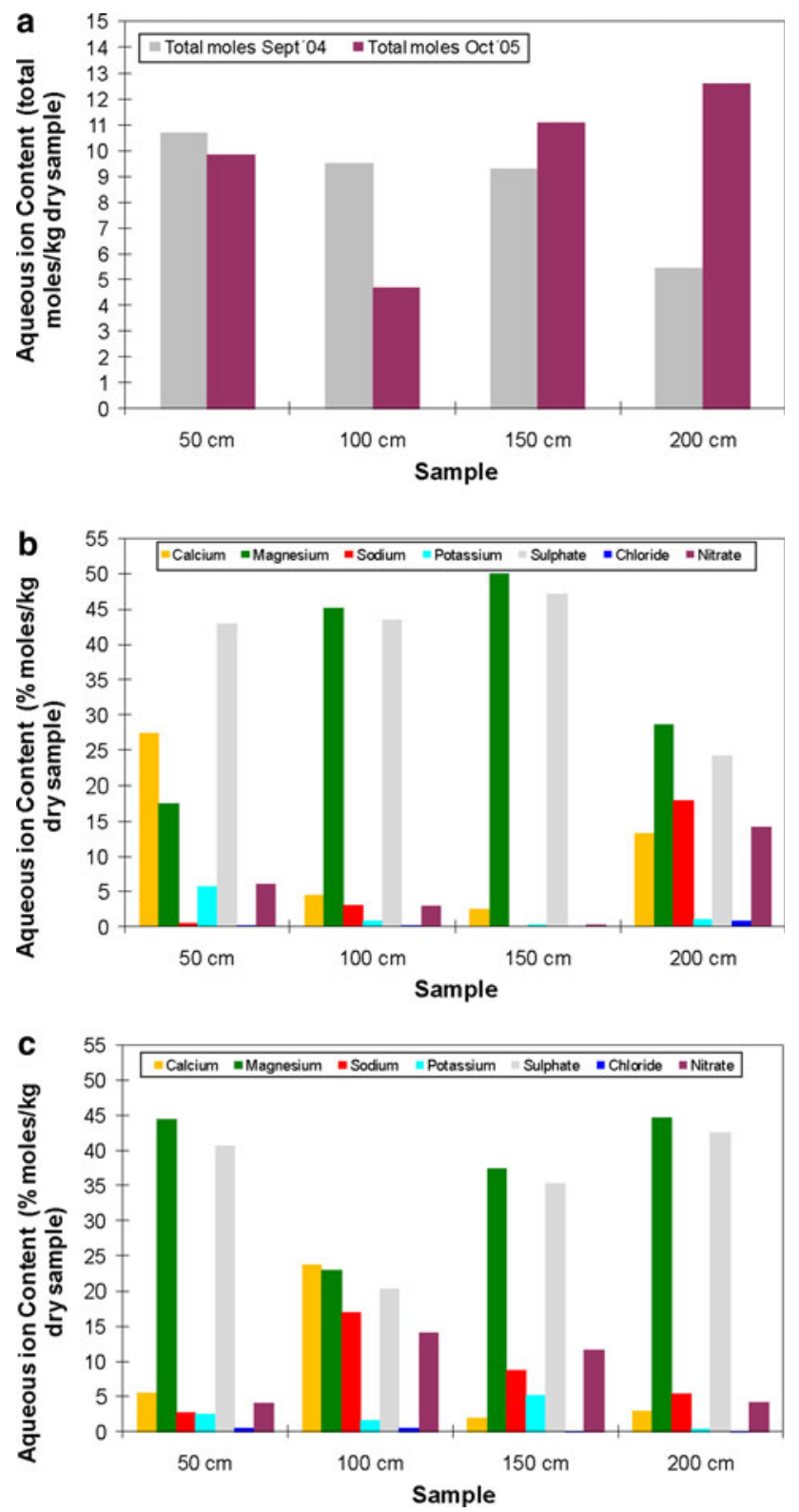

Fig. 8 IC analysis of efflorescences: a total ion content, b ion distribution (September 2004) and $\mathbf{c}$ ion distribution (October 2005)

the magnesium sulphate-water system the transition from hexahydrite to epsomite is expected at humidities just above $51 \%$, at room temperature, it is not observed until humidities of ca. $75 \%$ are reached (Steiger et al. 2008). However, despite this, it is clear that the transition from epsomite to hexahydrite occurs under the environmental conditions in the test site, as both phases were identified in efflorescence samples. Also, this does not affect other phase transitions occurring in the system. The thermodynamic calculations show several marked phase boundaries for sulphate, nitrate and chloride salts at around 65, 58, 50 and $28 \% \mathrm{RH}$, conditions which are within the range of those experienced in the test site. However, it is worth noting that no phase transition or precipitation is observed in the $\mathrm{RH}$ range of ca. 35-50\%. Changes in $\mathrm{RH}$ outside of this range occur during transition from winter to spring and from spring to summer. Temperature and relative humidity fluctuations occurring during these seasonal changes cause deliquescence of salts or salt mixtures present in the studied area, as well as the subsequent crystallization of other phases, which results in damage to the stone support. Control of the ambient RH within the monastery between these values may help to minimize the effect of salt crystallization.

Treatment testing and assessment

After inhibitor application in the test area, it was observed that the amount of the efflorescences developed in the control area was higher than in the treatment area (Fig. 2b, c). This was further confirmed by the weight recordings of the brushed material collected from both areas. This is in agreement with the results of laboratory tests carried out in batch crystallizers and in stone slabs (Ruiz-Agudo et al. 2006; Ruiz-Agudo et al. 2008). The laboratory tests indicated that while DTPMP acts as an inhibitor of epsomite crystallization when it is free in solution (batch crystallization experiments, change in crystal morphology), but in the stone, it seems to promote the growth of subflorescences without increasing the damage to the support. This is possibly due to the adsorption of phosphonates on calcite surfaces. Adsorbed phosphonate molecules act as a template for magnesium sulphate crystallization. Thus crystallization of epsomite takes place at lower supersaturation within the stone pore network. This model is borrowed from the well-accepted idea of template-assisted heterogeneous nucleation used in biomineralization to explain the crystallization of minerals assisted by organic molecules. Additionally, as it has been shown by Ruiz-Agudo (2007), this phosphonate layer may eventually protect the stone calcite surface against chemical weathering.

Nevertheless, it is still premature to draw conclusions on the potential positive or negative effects of the DTPMP inhibitor on $\mathrm{MgSO}_{4}$ crystallization damage on the basis of this single case study. In fact, as shown by previous experiments the behaviour of inhibitors strongly depends on several variables (e.g. concentration of the inhibitor, substrate, type of salt) (Lubelli and Van Hees 2007). Moreover, in practice a salt mixture is often present. Since some of these products may act to either inhibit or promote crystallization depending on the type of salt, further research should be carried out to study the effect of inhibitors on salt mixtures, and the implications of their use over longer periods of time. 

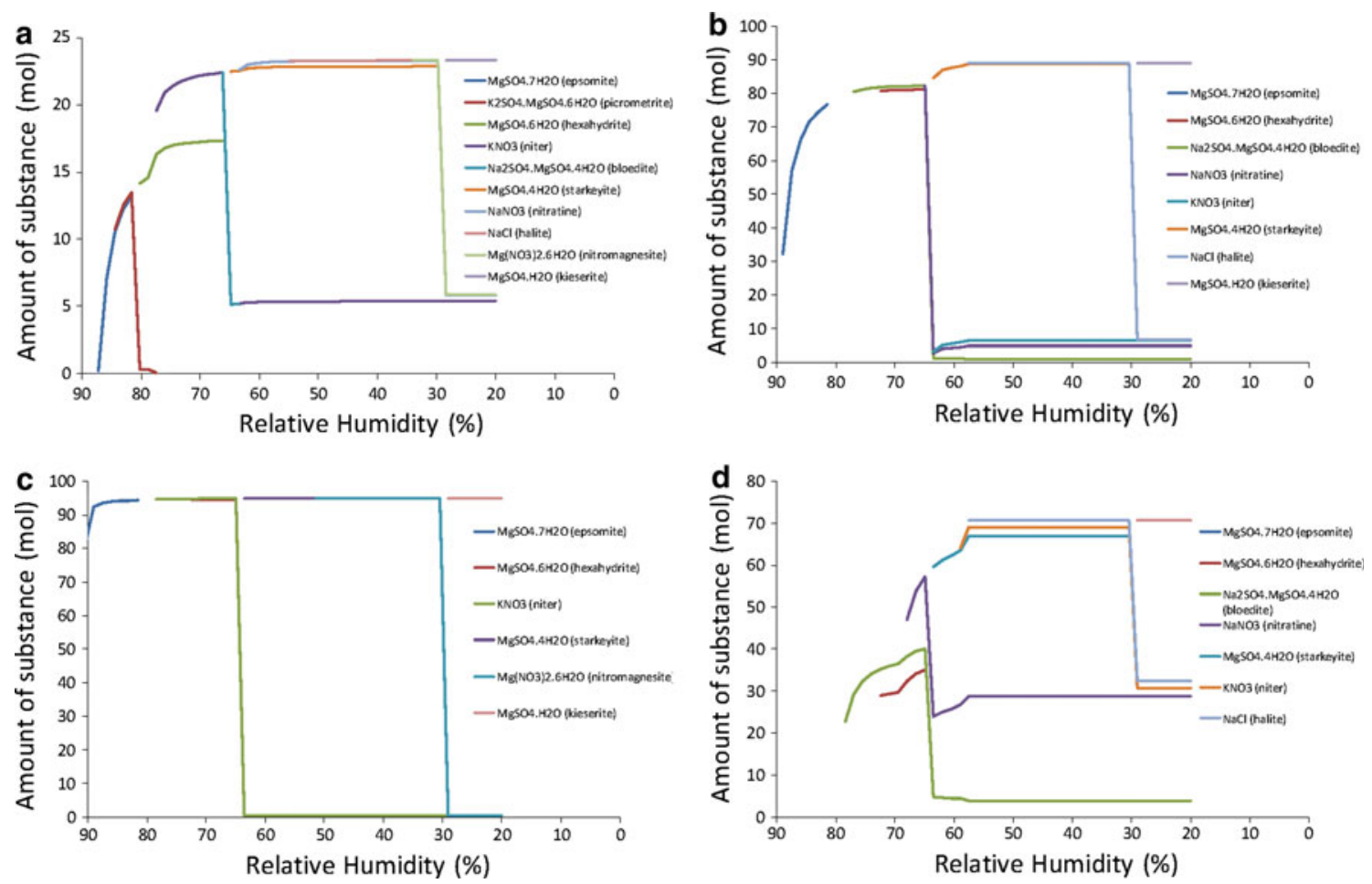

Fig. 9 Thermodynamic prediction of crystallization behaviour of efflorescence samples at $23^{\circ} \mathrm{C}$ taken at a $50 \mathrm{~cm}, \mathbf{b ~} 100 \mathrm{~cm}, \mathbf{c} 150 \mathrm{~cm}$ and d $200 \mathrm{~cm}$ above floor level

\section{Conclusions}

The research approach adopted in this study for the evaluation of the conservation state of St. Jeronimo Monastery aims to provide a sound approach for the assessment of salt decay phenomena in buildings. Salt damage is complex and results from the interaction of multiple factors. Accordingly, a wide range of aspects which may influence the development of damage were considered, which include the following: material properties of the object; moisture content and distribution; salt type, amount and distribution; and environmental conditions. The results of this study show that the sampling depth, location, and conditions of exposure affect the salt composition and content of the samples-all of which need to be assessed prior to undertaking treatment testing and assessment. The use of multiple analysis methods and techniques gave a coherent picture of the dynamic relationship between the condition of the stone, the activity of soluble salts and damage events, and the environmental conditions. Through this multidisciplinary approach a detailed diagnosis was achieved by performing a restricted number of wellfocused measurements, which will help to inform the development of suitable conservation strategies.

The combination of salt analyses, environmental monitoring and thermodynamic assessment has elucidated the impact of temperature and $\mathrm{RH}$ variation on the crystallization of salt mixtures in the wall. It has been shown that during the study period salts present in the wall were undergoing cycles of deliquescence and recrystallisation within the range of RH measured in the building, and hence the salt damage mechanism can be regarded as active. Thus control of the ambient RH within the building may help to minimize the effect of salt crystallization. The treatment trials using the DTPMP inhibitor have given some interesting preliminary results. While the selected inhibitor (an organophosphonate, DTPMP) appears to enhance the crystallization of magnesium sulphate (which was the main salt type found at the test site), enhanced damage was not observed. Although these preliminary results may appear promising, it is absolutely not possible to draw definitive conclusions on the basis of this single case study, and a great deal further research is needed to assess different inhibitors/substrate/salt combinations, together with rigorous on site testing to determine the longterm consequences of their use before their application on valuable objects could begin to be contemplated.

Acknowledgments This research was financed by the European Commission VIth Framework Program (contract no. SSP1-CT-2003501571), the Spanish Government under grant MAT2009-11332, and by research group RNM-179 (Junta de Andalucía, Spain). We thank CEAMA (Junta de Andalucía-Universidad de Granada) for their assistance with ESEM analysis. We are grateful to University of Eindhoven and the Institut für Mineralogie of the University of Münster, for the performance of IC and ICP-AES analysis. 


\section{References}

Arnold A, Zehnder K (1991) Monitoring wall paintings affected by soluble salts. In: Cather S (ed) The conservation of wall paintings. The Getty Conservation Institute, Los Angeles

Cardell C, Benavente D, Rodríguez-Gordillo J (2008) Weathering of limestone building material by mixed sulfate solutions. Characterization of stone microstructure, reaction products and decay forms. Mater Charact 59:1371-1385

Cardell-Fernández C (1998) Cristalización de sales en calcarenitas: aplicación al Monasterio de San Jerónimo, Granada (Salt crystalization in calcarenites: application to St. Jerónimo Monastery, Granada) (in Spanish). PhD, University of Granada, Spain

Goudie AS, Viles HA (1997) Salt weathering hazards. Wiley, London

Laue S (2005) Salt weathering of porous structures related to climate changes. Restoration of Buildings and Monuments (Bauinstandsetzen und Baudenkmalpflege) 11:1-10

Lubelli B, Van Hees RPJ (2007) Effectiveness of crystallization inhibitors in preventing salt damage in building materials. J Cult Heritage 8:223-234

Lubelli B, van Hees RPJ, Brocken HJP (2004) Experimental research on hygroscopic behaviour of porous specimens contaminated with salts. Constr Build Mater 18:339-348

Price CA (1996) Stone conservation: an overview of current research. The Getty Conservation Institute, Los Angeles

Price CA (2000) An expert chemical model for determining the environmental conditions needed to prevent salt damage in porous materials. European Commission Research Report No. 11, Protection and Conservation of European Cultural Heritage. Archetype Publications, London

Rodriguez-Navarro C (1994) Causas y mecanismos de alteración de los materiales calcáreos de las catedrales de Granada y Jaén (Causes and mechanisms of decay of the calcareous stones in the Granada and Jaen Cathedrals) (in Spanish). PhD, University of Granada, Spain

Rodriguez-Navarro C, Doehne E (1999) Salt weathering: influence of evaporation rate, supersaturation and crystallization pattern. Earth Surf Process Landf 24:191-209

Rodriguez-Navarro C, Doehne E, Sebastian E (2000) Influencing crystallization damage in porous materials through the use of surfactants: experimental results using sodium dodecyl sulfate and cetyldimethylbenzylammonium chloride. Langmuir $16: 947-954$
Rodriguez-Navarro C, Linares-Fernández L, Doehne E, Sebastian E (2002) Effects of ferrocyanide ions on $\mathrm{NaCl}$ crystallization in porous stone. J Cryst Growth 243:503-516

Rossi Menaresi R, Tucci A (1991) Pore structure and disruptive or cementing effect in salt crystallization in various types of stone. Stud Conserv 36:53-58

Ruiz-Agudo E (2007) Prevención del daño debido a la cristalización de sales en el patrimonio histórico construido mediante el uso de inhibidores de la cristalización (Prevention of salt damage to the built cultural heritage by the use of crystallisation inhibitors) (in Spanish). PhD, University of Granada, Spain

Ruiz-Agudo E, Rodriguez-Navarro C, Sebastian E (2006) The use of additives (phosphonates) as inhibitors for the crystallization of magnesium sulfate. In: Fort R, Alvarez de Buergo M, GomezHeras M, Vazquez-Calvo C (eds) Heritage, weathering and conservation. Balkema, New York

Ruiz-Agudo E, Mees F, Jacobs P, Rodriguez-Navarro C (2007) The role of saline solution properties on porous limestone salt weathering by magnesium and sodium sulfates. Environ Geol 52:269-281

Ruiz-Agudo E, Putnis CV, Rodriguez-Navarro C (2008) Interaction between epsomite crystals and organic additives. Cryst Growth Des 8:2665-2673

Sawdy A, Price C (2005a) Salt damage at Cleeve Abbey, England. Part I: a comparison of theoretical predictions and practical observations. J Cult Heritage 6:125-135

Sawdy A, Price C (2005b) Salt damage at Cleeve Abbey, England. Part II: seasonal variability of salt distribution and implications for sampling strategies. J Cult Heritage 6:361-367

Selwitz C, Doehne E (2002) The evaluation of crystallization modifiers for controlling salt damage to limestone. J Cult Heritage 3:20516

Steiger M (2005a) Crystal growth in porous materials-I: The crystallization pressure of large crystals. J Cryst Growth 282:455-469

Steiger M (2005b) Crystal growth in porous materials. II: Influence of crystal size on the crystallization pressure. J Cryst Growth 282:470-481

Steiger M, Linnow K, Juling H, Gülker G, Jarad AE, Von Ossietzky C, Brüggerhoff S, Kirchner D (2008) Hydration of $\mathrm{MgSO}_{4} \cdot \mathrm{H}_{2} \mathrm{O}$ and generation of stress in porous materials. Cryst Growth Des 8:336-343

Winkler EM (1994) Stone in architecture. Springer, Berlin Heidelberg 